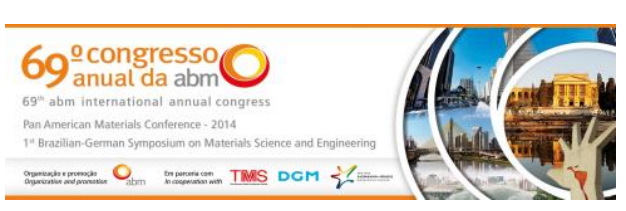

Tema: Iniciação Científico-Tecnológico

\title{
EFEITO DA ADIÇÃO DE ÁCIDO VERSÁTICO AO CYANEX 272 NA SEPARAÇÃO DE CÁLCIO, MAGNÉSIO E NÍQUEL CONTIDOS EM LICORES SINTÉTICOS SULFÚRICOS*
}

\author{
Alexandre Silva Guimarães ${ }^{1}$ \\ Priscila Siqueira da Silva ${ }^{2}$ \\ Marcelo Borges Mansur ${ }^{3}$
}

\section{Resumo}

O presente trabalho avaliou o comportamento de extração dos metais cálcio, magnésio e níquel, contidos em licores sintéticos sulfúricos, utilizando-se 0 extratante Cyanex $272(0,64 \mathrm{~mol} / \mathrm{L})$ e misturas entre Cyanex $272(0,64 \mathrm{~mol} / \mathrm{L})$ e ácido versático $(0,53 \mathrm{~mol} / \mathrm{L})$. Os resultados revelaram que a adição de ácido versático ao Cyanex 272 provocou um aumento nas extrações de cálcio, que atingiram cerca de $40 \%$ em $\mathrm{pH}=5,1$, decrescendo com a elevação do $\mathrm{pH}$ do licor até atingir aproximadamente em $15 \% \mathrm{pH}=5,9$. As extrações de níquel (em torno de $80 \%$ em $\mathrm{pH}=7,1$ ) foram favorecidas, enquanto as extrações de magnésio permaneceram em torno de 75-80\%, numa faixa de $\mathrm{pH}$ entre 6,0 e 7,0, em comparação com a utilização de apenas Cyanex 272 como extratante. O níquel pode ser separado dos metais cálcio e magnésio, pela mistura dos extratantes nas concentrações estudadas, em $\mathrm{pH}=5,1$, utilizando-se de 2 a 3 estágios de contactação.

Palavras-chave: Níquel; Cyanex 272; Ácido versático.

\section{EFFECT OF ADDITION OF VERSATIC ACID TO CYANEX 272 IN THE SEPARATION OF CALCIUM, MAGNESIUM AND NICKEL CONTAINED IN SYNTHETIC LIQUORS SULFURIC}

\section{Abstract}

This study evaluated the effect of extraction of the metals calcium, magnesium and nickel contained in sulfuric synthetic liquors, using the extractant Cyanex $272(0.64$ $\mathrm{mol} / \mathrm{L})$, and mixtures of Cyanex $272(0.64 \mathrm{~mol} / \mathrm{L})$ and versatic acid $(0.53 \mathrm{~mol} / \mathrm{L})$. The results showed that the addition of the versatic acid to Cyanex 272 caused an increase in the extraction of calcium, which reached about $40 \%$ at $\mathrm{pH}=5.1$, decreasing with increasing of $\mathrm{pH}$ of the liquor until it reaches approximately $15 \%$ in $\mathrm{pH}=5.9$. The extraction of nickel (about $80 \%$ at $\mathrm{pH}=7.1$ ) were favored, while the extraction of magnesium remained around $75-80 \%$, in a $\mathrm{pH}$ range between 6.0 and 7.0, compared to using just Cyanex 272 as extractant. The nickel can be separated from metals calcium and magnesium, by mixing these extractants at the concentrations studied, at $\mathrm{pH}=5.1$, using 2 to 3 stages.

Keywords: Nickel; Cyanex 272; Versatic acid.

\footnotetext{
Engenheiro Metalurgista, Mestre, Doutorando em Engenharia Metalúrgica, Materiais e de Minas, PPGEM, UFMG, Belo Horizonte, MG, Brasil.

2 Graduanda em Engenharia Metalúrgica, UFMG, Belo Horizonte, MG, Brasil.

3 Engenheiro Químico, Doutor, Prof. Associado, Dep. Eng. Metalúrgica e de Materiais, UFMG, Belo Horizonte, MG, Brasil.
}

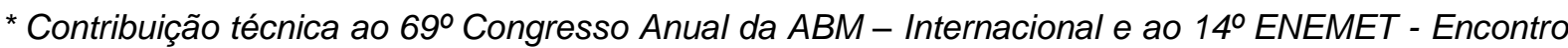
Nacional de Estudantes de Engenharia Metalúrgica, de Materiais e de Minas, 21 a 25 de julho de 2014, São Paulo, SP, Brasil.
} 


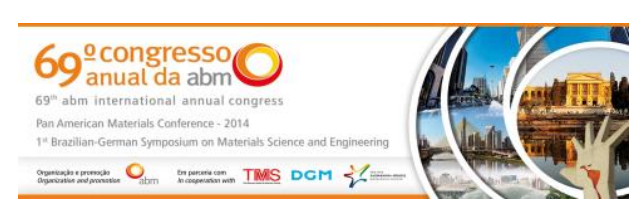

\section{INTRODUÇÃO}

A extração de níquel é feita, industrialmente, a partir de minérios lateríticos ou sulfetados utilizando-se processos hidrometalúrgicos. O níquel é um metal que possui grande interesse comercial acoplado à sua extração e, por isso, é necessário otimizar a sua obtenção gerando menor custo e maior eficiência. É largamente utilizado como elemento de liga em aços inoxidáveis e em superligas [1]. Os metais alcalinos terrosos, cálcio e magnésio, obtidos de forma secundária na extração de níquel, são bastante utilizados na obtenção de produtos industriais. O cálcio, na forma metálica, é utilizado na produção de cal virgem $(\mathrm{CaO})$ que está presente na composição dos vidros comerciais [2]. Além disso, ele pode ser encontrado como constituinte em ligas de chumbo e alumínio e como agente redutor na obtenção de outros metais atuando como desoxidante para o ferro, aço e cobre. Já o magnésio, encontrado usualmente na forma de óxidos ( $\mathrm{MgO}$ ), é utilizado na produção de materiais refratários e nas indústrias de borracha, fertilizantes e plásticos. Sua forma metálica ainda é utilizada na construção mecânica, principalmente nas indústrias aeronáutica e automobilística [2].

A rota processual hidrometalúrgica para a obtenção de níquel e dos metais alcalinos terrosos, provenientes de minérios sulfetados e/ou lateríticos, ocorre por meio de lixiviação sulfúrica sob pressão [3]. Após esta etapa, é obtido um licor contendo níquel, ferro, cálcio, cobalto, cobre, magnésio, manganês e zinco. O ferro é separado dos demais metais por precipitação elevando-se a temperatura do licor entre 150 e $200^{\circ} \mathrm{C}$ [4]. Os outros metais podem ser separados entre si utilizando a técnica de extração por solventes, que ocorre via contactação de uma fase aquosa, que neste contexto é o licor de lixiviação com uma fase orgânica, contendo um extratante específico solubilizado em diluente adequado. Guimarães [5] demonstrou que os metais cobalto, cobre, manganês e zinco podem ser extraídos do licor utilizando-se o extratante comercial Cyanex 272 (ácido 2,4,4-trimetil-pentil fosfínico), porém este extratante apresenta baixa seletividade na separação de níquel, cálcio e magnésio. Como a obtenção de um novo extratante para promover a extração de níquel ou dos metais alcalinos terrosos envolve elevados custos de investimentos, por volta de US\$ 3 milhões [6], uma alternativa atrativa consiste na mistura de dois ou mais extratantes comercialmente disponíveis para promover a separação e purificação destas espécies metálicas. Segundo Ndlovu e Mahlangu [3], o ácido versático, um tipo de ácido carboxílico, possui afinidade pelo níquel e, portanto, a combinação deste reagente juntamente com o Cyanex 272 pode constituir um potencial sistema extrator orgânico na separação de níquel, cálcio e magnésio. Neste contexto, o presente trabalho visou avaliar o efeito da extração de cálcio, magnésio e níquel misturando-se os extratantes Cyanex 272 e ácido versático, após etapas de pré-purificação com Cyanex 272 para remoção de cobalto, cobre, manganês e zinco.

\section{MATERIAIS E MÉTODOS}

Inicialmente, foi preparado um licor sintético sulfúrico cujas espécies e respectivas concentrações, similares às obtidas industrialmente, após a etapa de lixiviação sob pressão de minérios lateríticos de níquel, estão apresentadas na Tabela 1.

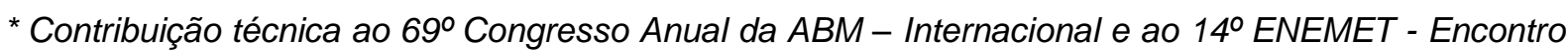
Nacional de Estudantes de Engenharia Metalúrgica, de Materiais e de Minas, 21 a 25 de julho de 2014, São Paulo, SP, Brasil.
} 


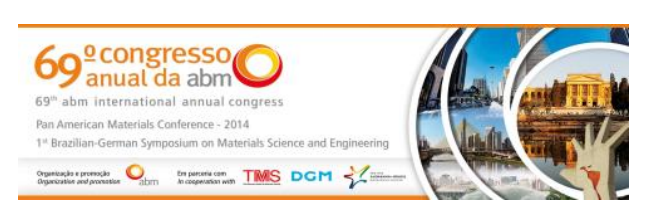

Tabela 1. Composição química do licor sintético sulfúrico

\begin{tabular}{ccccc}
\hline Espécie & $\mathrm{Ni}^{2+}$ & $\mathrm{Mg}^{2+}$ & $\mathrm{Ca}^{2+}$ & $\mathrm{SO}_{4}{ }^{2-}$ \\
\hline Concentração $(\mathrm{mol} / \mathrm{L})$ & 1,500 & 0,125 & 0,013 & 1,638 \\
\hline
\end{tabular}

Os reagentes $\mathrm{NiSO}_{4} .6 \mathrm{H}_{2} \mathrm{O}, \mathrm{MgSO}_{4} .7 \mathrm{H}_{2} \mathrm{O}, \mathrm{CaSO}_{4} .2 \mathrm{H}_{2} \mathrm{O}, \mathrm{H}_{2} \mathrm{SO}_{4}$, (de grau analítico, marca Synth, pureza > 98\%), foram solubilizados em água destilada. Posteriormente, o licor sintético sulfúrico obtido, foi submetido à filtração para remoção de eventuais sólidos em suspensão.

\subsection{Fase Orgânica}

\subsubsection{Cyanex 272}

O Cyanex 272 (ácido 2,4,4-trimetil-pentil fosfínico) é uma molécula orgânica derivada de ésteres ortofosfóricos, ácidos fosfóricos e ácidos fosfínicos [7]. Sua massa molecular é $290 \mathrm{~g} / \mathrm{mol}$ e possui densidade de $0,92 \mathrm{~g} / \mathrm{cm}^{3}$ à temperatura ambiente. Neste estudo, a amostra utilizada foi fornecida pela Cytec Canada. A fórmula estrutural do Cyanex 272 é apresentada na Figura 1:

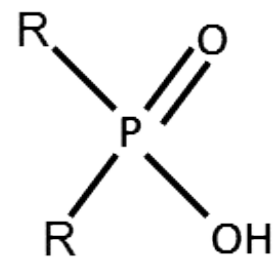

$$
\mathrm{R}=\mathrm{CH}_{3} \mathrm{C}\left(\mathrm{CH}_{3}\right) \mathrm{CH}_{2} \mathrm{CH}\left(\mathrm{CH}_{3}\right) \mathrm{CH}_{2}
$$

Figura 1. Representação da estrutura molecular do Cyanex 272.

\subsection{2 Ácido versático}

O ácido versático, também chamado de ácido neodecanóico, é um composto orgânico sintético. Sua massa molecular é $172 \mathrm{~g} / \mathrm{mol}$ e apresenta densidade de 0,91 $\mathrm{g} / \mathrm{cm}^{3}$ à temperatura ambiente. Na Figura 2, é apresentada a estrutura molecular do ácido versático.

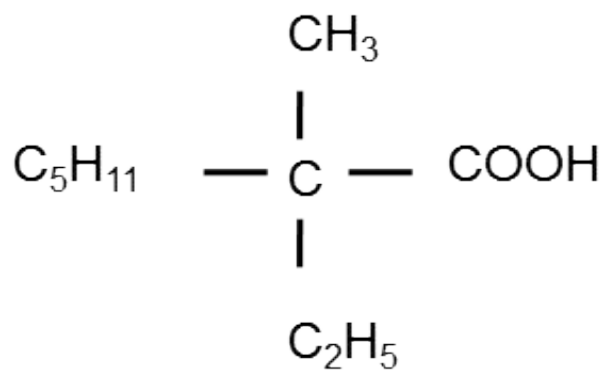

Figura 2. Representação da estrutura molecular do Ácido Versático.

Os extratantes Cyanex 272 e ácido versático foram solubilizados em n-heptano $\left(\mathrm{C}_{7} \mathrm{H}_{16}\right)$, o qual foi utilizado como diluente.

\subsection{Ensaios de Extração por Solventes}

Os ensaios de extração por solventes foram realizados a partir da contactação das fases aquosa e orgânica na mesma proporção em volume: $200 \mathrm{~mL}$ do licor $+200 \mathrm{~mL}$

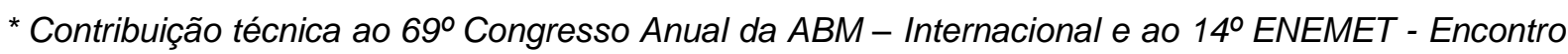
Nacional de Estudantes de Engenharia Metalúrgica, de Materiais e de Minas, 21 a 25 de julho de 2014, São Paulo, SP, Brasil. 
Engenharia Metalúrgica e Materiais da UFMG. A concentração dos metais na solução orgânica foi obtida por balanço de massa a partir dos valores determinados analiticamente da fase aquosa.

\section{RESULTADOS E DISCUSSÃO}

Para avaliar a reprodutibilidade dos dados, alguns ensaios foram repetidos aleatoriamente e mostraram-se dentro da faixa de confiabilidade de $5 \%$, ou seja, os dados são reprodutíveis.

A extração percentual dos metais foi calculada pela equação (1):

$$
E(\%)=\frac{[C]_{i}-[C]}{[C]_{i}} \times 100 \%
$$

em que [C]i corresponde a concentração inicial de cada metal na fase aquosa e [C] representa a concentração do metal no refinado (concentração do metal em cada valor de $\mathrm{pH}$ analisado).

Para avaliar o efeito da adição do ácido versático (0,53 mol/L) ao Cyanex $272(0,64$ $\mathrm{mol} / \mathrm{L}$ ) no comportamento extrativo dos metais cálcio, magnésio e níquel, em relação ao sistema extrator contendo apenas Cyanex 272 (0,64 mol/L), são mostradas na Figura 4 comparativamente, as curvas de extração particular de cada metal.

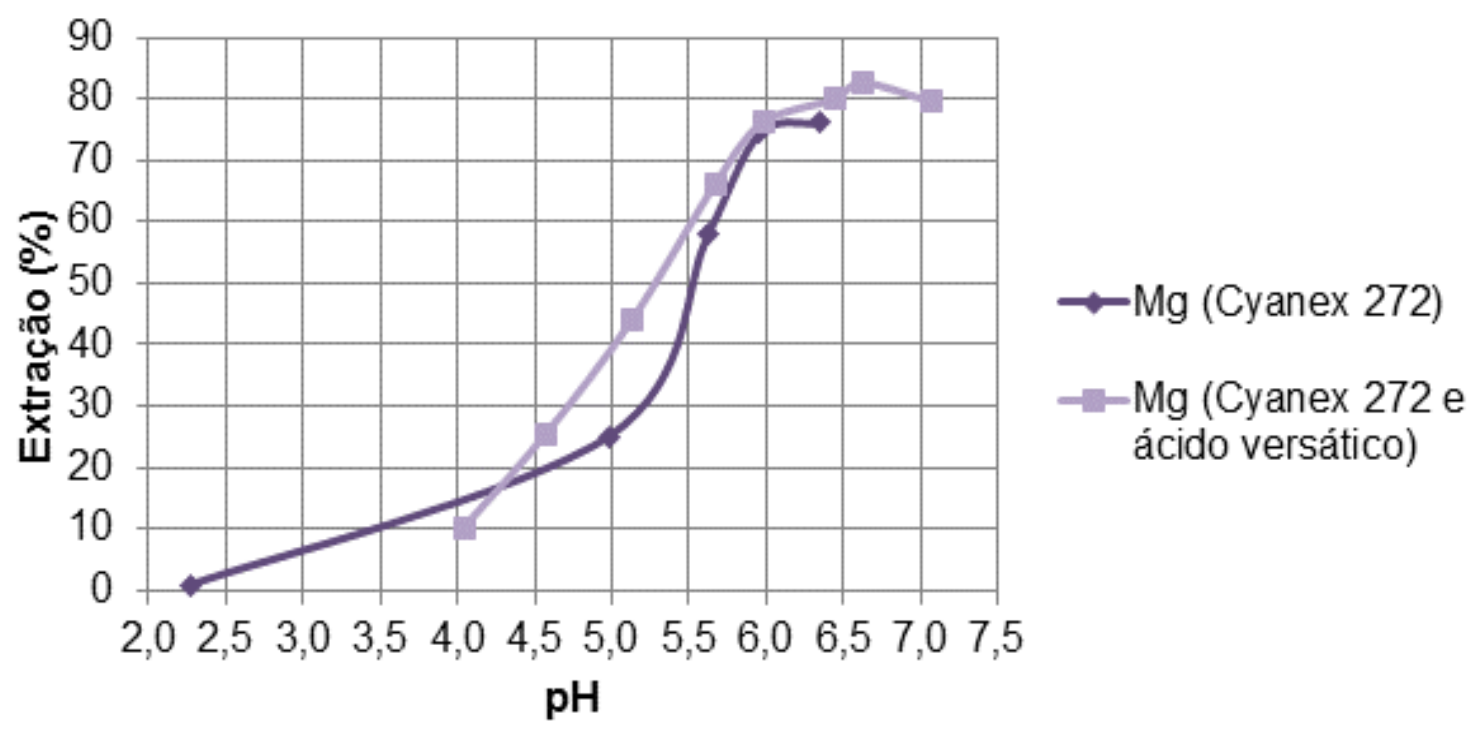

(a)

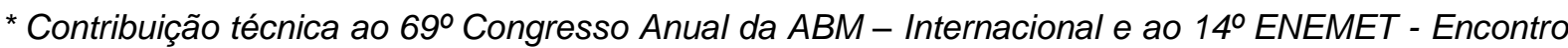
Nacional de Estudantes de Engenharia Metalúrgica, de Materiais e de Minas, 21 a 25 de julho de 2014, São Paulo, SP, Brasil.
} 

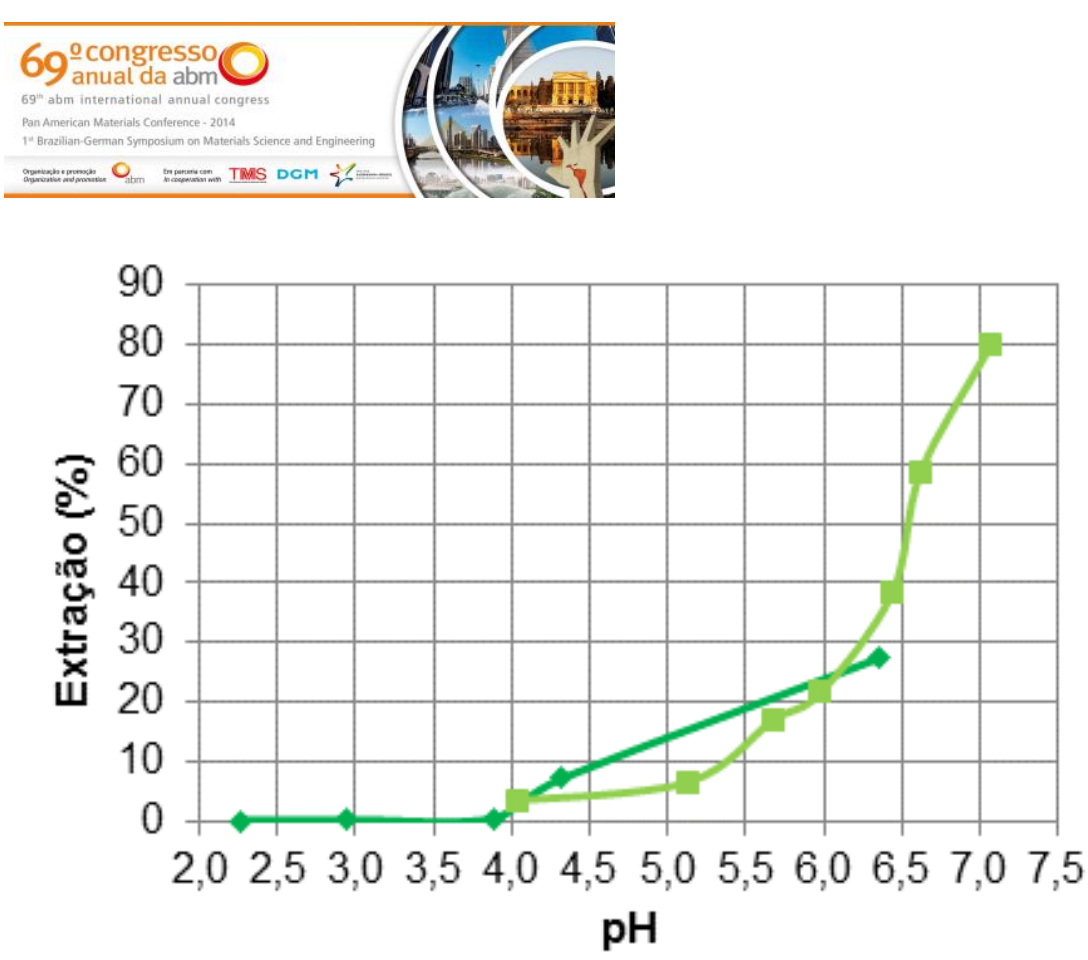

$\rightarrow$ Ni (Cyanex 272)

-Ni (Cyanex 272 e ácido versático)

(b)

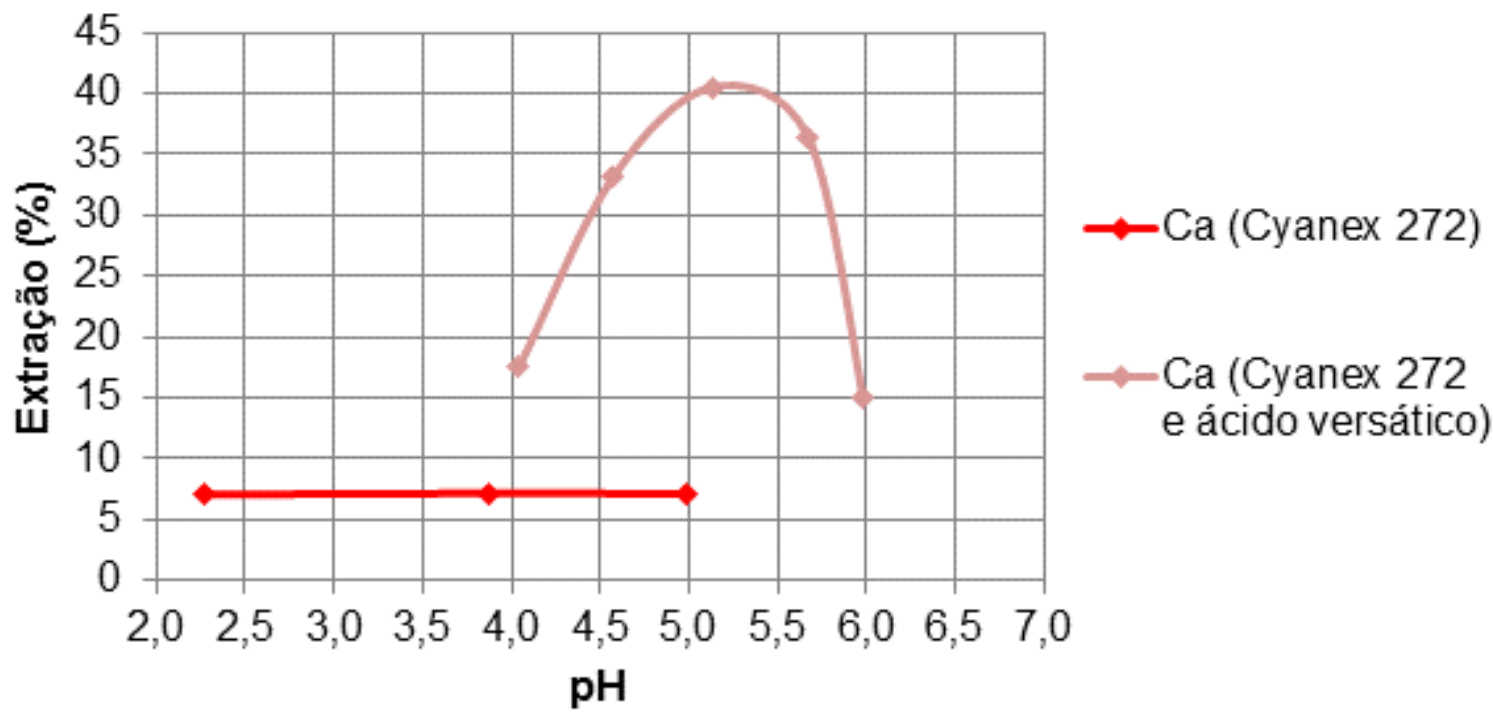

(c)

Figura 4. Extração dos metais (a) magnésio, (b) níquel e (c) cálcio utilizando-se 0,64 mol/L de Cyanex 272 e misturas entre $0,64 \mathrm{~mol} / \mathrm{L}$ de Cyanex 272 e $0,53 \mathrm{~mol} / \mathrm{L}$ de ácido versático $\left(T=50^{\circ} \mathrm{C}\right.$; $\mathrm{A} / \mathrm{O}=1)$.

De um modo geral, a adição de ácido versático $(0,53 \mathrm{~mol} / \mathrm{L})$ ao Cyanex 272 $(0,64 \mathrm{~mol} / \mathrm{L})$ provocou um pequeno aumento nas extrações de magnésio que aumentaram de aproximadamente $75 \%$ (quando apenas o Cyanex 272 foi utilizado como extratante), em pH igual a 6,4, para cerca de $80 \%$, em pH igual 7,1. Além disso, é possível observar que a combinação destes extratantes deslocou sutilmente para condições um pouco mais ácidas (para a esquerda) a isoterma de extração deste metal alcalino terroso. Para valores de $\mathrm{pH}$ maiores que 4,0 , as extrações de magnésio pela mistura de Cyanex 272 e ácido versático são ligeiramente superiores às extrações desta espécie metálica pelo Cyanex 272. Portanto, a presença de ácido versático na fase orgânica contendo o Cyanex 272 pouco afetou ou influenciou as extrações de magnésio.

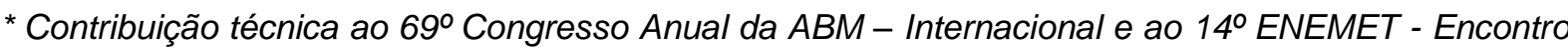
Nacional de Estudantes de Engenharia Metalúrgica, de Materiais e de Minas, 21 a 25 de julho de 2014, São Paulo, SP, Brasil.
} 


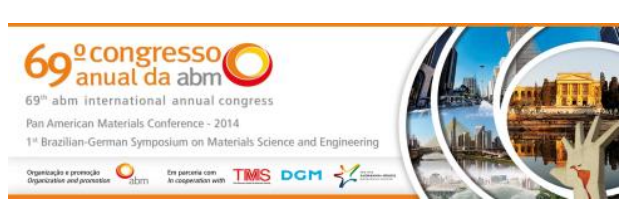

Em relação ao níquel (Figura 4(b)), o acréscimo de ácido versático favoreceu as extrações deste metal que atingiram cerca de $80 \%$ em $\mathrm{pH}$ igual a $7,1 \mathrm{em}$ comparação com o sistema extrator contendo apenas Cyanex 272 (aproximadamente 25\% de extração em pH igual a 6,4). Este fato pode indicar maior afinidade e disponibilidade do ácido versático em reagir com o níquel formando um complexo, $\mathrm{R}_{2} \mathrm{Ni}_{2} \mathrm{RH}$, conforme mostrado pela equação (2) [3]:

$4 \mathrm{RH}_{(\text {org })}+\mathrm{Ni}^{2+}{ }_{(\mathrm{aq})} \rightleftharpoons \mathrm{R}_{2} \mathrm{Ni}_{2} \mathrm{RH}_{(\text {org })}+2 \mathrm{H}^{+}(\mathrm{aq})$

em que $\mathrm{RH}$ representa a molécula de ácido versático e os subscritos (org) e (aq) correspondem as espécies solúveis nas fases orgânica e aquosa respectivamente.

As extrações de cálcio (Figura 4(c)), na ausência de ácido versático, são desfavorecidas pelo uso de Cyanex $272(0,64 \mathrm{~mol} / \mathrm{L})$, extrações inferiores a 10\% em toda a faixa de $\mathrm{pH}$ estudada (entre 2,0 e 7,0), revelando a menor afinidade que este extratante possui em relação a esta espécie metálica. Com a adição de ácido versático $(0,53 \mathrm{~mol} / \mathrm{L})$ a fase orgânica contendo Cyanex $272(0,64 \mathrm{~mol} / \mathrm{L})$, observase um aumento nas extrações de cálcio que atingiram um ponto máximo de extração (cerca de $40 \%$ em $\mathrm{pH}=5,1$ ). Com a elevação do $\mathrm{pH}$ licor, é possível notar que ocorre uma diminuição no percentual de extração deste metal, que atinge aproximadamente $15 \%$ de extração em pH igual a 5,9. Isso ocorre pela provável competição e troca catiônica entre cálcio e níquel pelos extratantes Cyanex 272 (0,64 mol/L) e ácido versático $(0,53 \mathrm{~mol} / \mathrm{L})$.

Na Figura 5, são mostradas as curvas de extração dos metais cálcio, magnésio e níquel, em função do pH, visando-se avaliar a separação destes metais contidos no licor sintético sulfúrico.

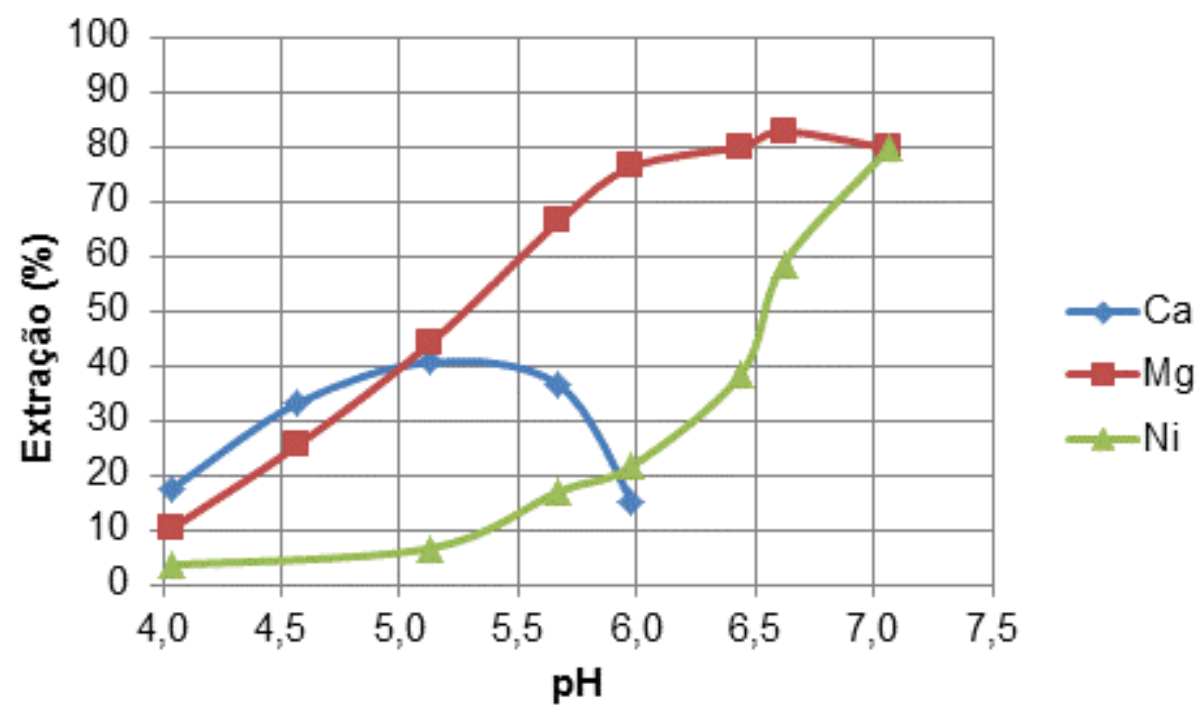

Figura 5. Curvas de extrações conjuntas dos metais cálcio, magnésio e níquel utilizando-se 0,64 $\mathrm{mol} / \mathrm{L}$ de Cyanex 272 e $0,53 \mathrm{~mol} / \mathrm{L}$ de ácido versático, $\mathrm{T} 50^{\circ} \mathrm{C} ; \mathrm{A} / \mathrm{O}=1$.

A análise conjunta das curvas de extração (Figura 5) permite observar que numa faixa de $\mathrm{pH}$ entre 4,0 e 5,5 , os metais cálcio e magnésio são extraídos majoritariamente para a fase orgânica em detrimento do níquel. Desta maneira, em $\mathrm{pH}$ igual a 5,0, é possível promover a purificação do licor sintético sulfúrico em relação ao níquel, uma vez que são extraídos cerca de $40 \%$ de cada um dos metais

* Contribuição técnica ao 69 Congresso Anual da ABM - Internacional e ao 14ํㅡㄹ ENEMET - Encontro Nacional de Estudantes de Engenharia Metalúrgica, de Materiais e de Minas, 21 a 25 de julho de 2014, São Paulo, SP, Brasil. 


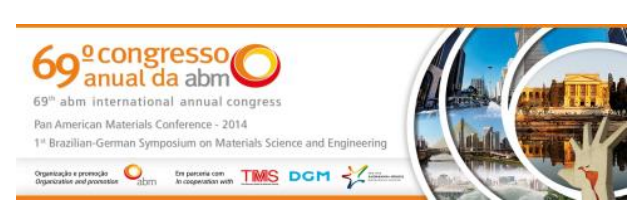

(cálcio e magnésio) conjuntamente com baixos teores de níquel (em torno de 6\%), podendo ser utilizados dois ou três estágios de contactação para se obter cerca de pelo menos $82 \%$ de níquel purificado em fase aquosa, o que permite a utilização deste sistema extrator em ambiente industrial para a separação e purificação de níquel. Para valores de $\mathrm{pH}>6,0$, a separação destes metais é dificultada pelo fato de elevados teores de magnésio e de níquel serem extraídos simultaneamente do licor.

\section{CONCLUSÃO}

Este trabalho avaliou o efeito da adição de ácido versático $(0,53 \mathrm{~mol} / \mathrm{L})$ ao Cyanex $272(0,64 \mathrm{~mol} / \mathrm{L})$ na extração dos metais cálcio, magnésio e níquel contidos em licores sintéticos sulfúricos. As principais conclusões são:

- A presença do ácido versático $(0,53 \mathrm{~mol} / \mathrm{L})$ nas soluções orgânicas contendo Cyanex $272(0,64 \mathrm{~mol} / \mathrm{L})$ favoreceu as extrações de cálcio, que atingiram cerca de $40 \%$ em pH igual a 5,1, em comparação com o uso de apenas Cyanex $272(0,64 \mathrm{~mol} / \mathrm{L})$, que extraiu teores de cálcio inferiores a 10\% em toda a faixa de $\mathrm{pH}$ estuda entre 2,0 e 7,0. Foi observado que com a elevação do $\mathrm{pH}$ do licor, as extrações de cálcio diminuíram para cerca de $15 \% \mathrm{em} \mathrm{pH}$ igual a 5,9, sugerindo uma provável competição e troca catiônica entre cálcio e níquel pelos extratantes Cyanex 272 e ácido versático nas concentrações utilizadas neste estudo;

- A mistura de 0,53 mol/L de ácido versático e 0,64 mol/L de Cyanex 272 pouco influenciou as extrações de magnésio, que atingiram em torno de $80 \% \mathrm{em} \mathrm{pH}$ $=7,1$, em comparação com $75 \%$ de extração deste metal em $\mathrm{pH}=6,4$ pelo uso de Cyanex $272(0,64 \mathrm{~mol} / \mathrm{L})$;

- A adição de 0,53 mol/L de ácido versático ao Cyanex $272(0,64 \mathrm{~mol} / \mathrm{L})$ aumentou as extrações de níquel, que alcançaram cerca de $80 \% \mathrm{em} \mathrm{pH}=$ 7,1 , em relação as extrações realizadas apenas com Cyanex $272(0,64 \mathrm{~mol} / \mathrm{L})$ na fase orgânica (extrações em torno de $25 \%$ em pH =6,4);

- O licor sintético sulfúrico pode ser purificado, em $\mathrm{pH}=5,0$, pelo fato de a mistura formada por $0,64 \mathrm{~mol} / \mathrm{L}$ de Cyanex $272 \mathrm{com} 0,53 \mathrm{~mol} / \mathrm{L}$ de ácido versático extrair preferencialmente cerca de $40 \%$ de cada um dos metais, cálcio e magnésio, simultaneamente com baixos teores de níquel (em torno de $6 \%$ ) possibilitando a separação do níquel em relação aos metais, cálcio e magnésio, em dois ou três estágios de contactação, podendo-se obter pelo menos, cerca de $82 \%$ de níquel purificados em solução aquosa, permitindo a viabilidade de utilização deste sistema extrator em processos industriais de separação e purificação de níquel.

\section{Agradecimentos}

Os autores deste trabalho agradecem ao laboratório de análises químicas (LAQ) do departamento de Engenharia Metalúrgica e de Materiais (UFMG) pelas análises realizadas. Também agradecem à Cytec pelo fornecimento de Cyanex 272, ao apoio financeiro do CNPq (CT-Mineral, Processo 550243/2011-9), ao CNPq, à FUMP/UFMG, à FAPEMIG, à CAPES e ao INCT-Acqua (Instituto Nacional de Ciência e Tecnologia em Recursos Minerais, Água e Biodiversidade www.acquainct.org).

\footnotetext{
* Contribuição técnica ao $69^{\circ}$ Congresso Anual da ABM - Internacional e ao 14ํㅡㄹ ENEMET - Encontro Nacional de Estudantes de Engenharia Metalúrgica, de Materiais e de Minas, 21 a 25 de julho de 2014, São Paulo, SP, Brasil.
} 
